\title{
Late life bipolar disorder evolving into frontotemporal dementia mimic
}

\author{
This article was published in the following Dove Press journal: \\ Neuropsychiatric Disease and Treatment \\ 7 September 2016 \\ Number of times this article has been viewed
}

\author{
Annemiek Dols' \\ Welmoed Krudop ${ }^{2}$ \\ Christiane Möller ${ }^{2}$ \\ Kenneth Shulman ${ }^{3}$ \\ Martha Sajatovic ${ }^{4}$ \\ Yolande AL Pijnenburg ${ }^{2}$ \\ 'Department of Old Age Psychiatry, \\ GGZInGeest, ${ }^{2}$ Alzheimer Centre \\ and Department of Neurology, \\ Neuroscience Campus Amsterdam, \\ VU University Medical Centre, \\ Amsterdam, the Netherlands; \\ ${ }^{3}$ Department of Geriatric Psychiatry, \\ Sunnybrook Health Science Centre, \\ Faculty of Medicine, University \\ of Toronto, Toronto, Canada; \\ ${ }^{4}$ Department of Psychiatry and \\ Neurology, Case Western Reserve \\ University School of Medicine, \\ University Hospitals Case Medical \\ Center, Cleveland, OH, USA
}

Objectives: Although bipolar disorder has been understood classically as a cyclic disease with full recovery between mood episodes, in the last decade, evidence has accumulated supporting progressive features. The clinical picture of advanced or end-stage bipolar disorder is heterogeneous with possible deficits in cognition and behavior, as illustrated by our case series.

Cases: From our neuropsychiatric outpatient clinic, we describe four cases with bipolar disorder gradually developing a clinical syndrome, including apathy, disinhibition, loss of empathy, stereotypical behavior, and compulsiveness, fulfilling the criteria for possible behavioral variant frontotemporal dementia. All cases were diagnosed with bipolar 1 disorder at least 10 years before the onset of the current symptoms, which were not due to recent mood episodes or switches of medication. In all cases, 3-7 years of follow-up yielded no progression. Repeated neuroimaging was within normal limits. Cerebrospinal fluid biomarker studies were not supportive of underlying neurodegenerative pathology. C9orf72 mutation status was negative in all cases.

Conclusion: Symptoms fitting the criteria for possible behavioral variant frontotemporal dementia may be present in end-stage of bipolar disorder. An alternative neurodegenerative nature seems unlikely based on repeated normal neuroimaging and the absence of clinical progression. Functional involvement of the frontal-subcortical networks might play a role.

Keywords: bipolar disorder, older, staging, bvFTD, benign phenocopy syndrome

\section{Introduction}

Although bipolar disorder has been classically considered a cyclic disease with full recovery between mood episodes, in the last decade, evidence has accumulated supporting the notion that bipolar disorder is a progressive condition with functional decline over time. In older patients with bipolar disorder, several studies have confirmed a significant cognitive dysfunction ${ }^{1}$ that was not associated with mood or prodromal phase of dementia. ${ }^{2-6}$ Similarly, magnetic resonance imaging (MRI) findings in older bipolar patients have shown regional gray matter volume reduction and white matter hyperintensities $^{7-10}$ that were not consistent with a dementia profile but hypothesized to be correlated with disease duration ${ }^{11}$ or a result from the toxic effects of recurrent mood episodes. ${ }^{12}$ The cognitive dysfunction and mild structural brain alterations seen in patients with bipolar disorder suggest a model of accelerated aging. ${ }^{13-16}$ The clinical stages of bipolar disorder can range from a latent or asymptomatic form (stage 0 ) to a chronic, end-stage presentation (stage IV). Accelerated aging defines the later stages of bipolar disorder. ${ }^{14-16}$ The clinical picture of end-stage bipolar disorder is heterogeneous with possible cognitive and behavioral deficits. Here, we report a series of four male cases diagnosed with bipolar disorder who subsequently developed gradually progressive behavioral and social-emotional changes rather similar to behavioral variant
Correspondence: Annemiek Dols Department of Old Age Psychiatry, GGZInGeest, Amstelveenseweg 589, I08IJC, Amsterdam, the Netherlands Tel +3I 207885565

Fax +3। 207885577

Email a.dols@ggzingeest.nl
Neuropsychiatric Disease and Treatment 2016:12 2207-22/2

2207

Dovepress f in 0

http://dx.doi.org/1 0.21 147/NDT.S99229 (c) (1) (5) 2016 Dols et al. This work is published and licensed by Dove Medical Press Limited. The full terms of this license are available at https://www.dovepress.com/terms.php cc) ${ }_{\mathrm{BY}} \mathrm{NC}$ and incorporate the Creative Commons Attribution - Non Commercial (unported, v3.0) License (http://creativecommons.org/licenses/by-n/3.0/). By accessing the work you hereby accept the Terms. Non-commercial uses of the work are permitted without any further permission from Dove Medical Press Limited, provided the work is properly attributed. For permission for commercial use of this work, please see paragraphs 4.2 and 5 of our Terms (https://www.dovepress.com/terms.php). 
frontotemporal dementia (bvFTD). A neurodegenerative nature of this condition, however, could not be demonstrated after 3-7 years of extensive clinical follow-up. We propose that a nonprogressive frontal lobe syndrome constitutes a possible manifestation of end-stage bipolar disorder.

\section{Cases}

The Medical Ethical Committee of the VU Medical Centre, Amsterdam, approved the study. All patients provided written informed consent to publish patient data. As a tertiary neuropsychiatric center, we have specialized in diagnosis of patients presenting with behavioral symptoms in later life. All patients undergo a psychiatric, neurological, and neuropsychological examination and an MRI scan at initial presentation. Most patients also undergo a lumbar puncture with determination of cerebrospinal fluid (CSF) biomarkers for neurodegeneration. In each case, a consensus diagnosis is made by a neurologist and a psychiatrist with consecutive follow-up. As we have no possibilities for outreaching care, most of our patients are treated by local mental health organizations or memory clinics. Here, we describe four cases, all alive after a follow-up of 3-7 years.

\section{Case I}

A 78-year-old male, diagnosed with bipolar 1 disorder at the age of 18 , was referred to our memory clinic because of gradually progressive behavioral change. Although the patient had no complaints, his wife described changes starting several years ago consisting of excessive consumption of cheese, diminished empathy, and sitting on the couch all day smoking excessively. Over the years, he began to masturbate in public and demonstrated excessive clock watching. He lost the ability to spontaneously initiate conversations and echoed other people's words. Over time, he developed urinary and fecal incontinence due to personal neglect. His family history revealed a brother with schizophrenia and several first degree family members with depression (Table 1).

He had previously been admitted three times, but his mood had been stable for over 10 years with use of lithium and zuclopentixol. There was no concurrent mood or psychotic symptoms. Lithium serum levels were within the therapeutic range $(0.4-0.8 \mathrm{mmol} / \mathrm{L})$ and a dose reduction did not change his behavior. Mild extrapyramidal features on the neurological examination were attributed to medication use. With respect to cognitive performance, memory problems were not reported, but his spatial orientation was impaired. Mini-Mental State Examination (MMSE) was $27 / 30$ and frontal assessment battery (FAB) was 14/18. At neuropsychological examination, a predominant executive dysfunction was found. Repeated MMSE and FAB scores were 29/30 and 12/18, respectively, after 5 years. Repeated MRI of the brain yielded no abnormalities and $\left[{ }^{18} \mathrm{~F}\right]-2-d e o x$ y-2-fluoro-D-glucose positron emission tomography (FDGPET) scans were repeatedly normal. CSF levels of tau and phosphorylated tau were slightly elevated, with normal CSF level of amyloid beta-42. There were no mutations found in the Microtubule-Associated Protein Tau (MAPT)-gen, progranulin (GRN)-gen, or Presenilin-1 protein (PSEN1)-gen, nor a repeat expansion in the chromosome 9 open reading frame 72 (C9ORF72)-gen. After 7 years of follow-up at our memory clinic, it was concluded that this very slowly progressive frontal syndrome was not due to bipolar mood symptoms or a neurodegenerative disease, such as bvFTD.

\section{Case 2}

A 70-year-old male attended our memory clinic because of forgetfulness and word-finding difficulties of 4 years' duration. He had been diagnosed with bipolar 1 disorder 17 years ago after a serious suicide attempt and successfully stabilized with lithium (Table 1). Three years ago, these same memory complaints made him discontinue lithium abruptly, and a depressive relapse followed. At initial memory clinic presentation, he was on carbamazepine and mirtazapine, without any significant mood symptoms. His wife and daughter reported a gradual change of behavior while his mood was euthymic. He became more focused on religion, impulsively bought a car, and lived by a rigid daily routine. Moreover, inappropriate social behavior was reported, such as visiting the swimming pool without his dentures. There was a gradual loss of empathy. His family history was negative for psychiatric disorders, but positive for dementia in two grandmothers. On examination using standardized rating scales, his MMSE was 25/30 and FAB 12/18. He exhibited a moderate score on the stereotypy rating scale (SRI 8/60). Repeated neuropsychological examination revealed nonprogressive mild executive and episodic memory disturbances with decreased mental speed. His MMSE was 29/30 after 6 years, with a FAB score of $17 / 18$. MRI scans of the brain were repeatedly within the normal range for his age. CSF levels of amyloid beta-42, tau, and phosphorylated tau were all within the normal range. After a follow-up of 6 years, his behavior remained stable and could not be attributed to bipolar mood symptoms or a neurodegenerative disease, such as bvFTD.

\section{Case 3}

A 65-year-old male reported no complaints when visiting a memory clinic, although he admitted that he had always been controlling and compulsive, with an urge of excessive cleaning. He had been diagnosed with bipolar disorder and 
Table I Characteristics of the four cases

\begin{tabular}{|c|c|c|c|c|}
\hline & Case I & Case 2 & Case 3 & Case 4 \\
\hline \multicolumn{5}{|c|}{ Clinical and sociodemographic characteristics } \\
\hline Age (years) & 78 & 70 & 65 & 62 \\
\hline Sex & Male & Male & Male & Male \\
\hline Education in years & 6 & II & 13 & 13 \\
\hline $\begin{array}{l}\text { Age at onset bipolar disorder } \\
\text { (years) }\end{array}$ & 18 & 53 & 51 & 28 \\
\hline Number of admissions & 3 & I & 2 & $>2$ \\
\hline Family history (First degree) & Psychiatry & Cardiovascular & Cardiovascular & Cardiovascular \\
\hline Somatic history & Diabetes & Myocardial infarction & $\begin{array}{l}\text { Chronic obstructive } \\
\text { pulmonary disease }\end{array}$ & Diabetes \\
\hline \multirow[t]{4}{*}{ Psychopharmaca } & Lithium 800 mg & Lithium I,200 mg & Quetiapine 400 mg & Lithium 800 mg \\
\hline & Zuclopentixol 6 mg & & Phenelzine $45 \mathrm{mg}$ & Olanzapine 2.5 mg \\
\hline & & & Temazepam 20 mg & \\
\hline & & & Oxazepam 50 mg & \\
\hline \multicolumn{5}{|l|}{ Rascovsky criteria } \\
\hline Disinhibition & + & + & + & + \\
\hline Apathy & + & & & + \\
\hline Loss of empathy & & + & + & \\
\hline Stereotypical behavior & + & + & + & + \\
\hline Eating behavior & + & & & + \\
\hline Executive dysfunction & + & & + & \\
\hline \multicolumn{5}{|l|}{ Neuropsychology } \\
\hline MMSE at presentation & 28 & 25 & 27 & 28 \\
\hline MMSE after follow-up & 29 & 29 & 23 & 29 \\
\hline $\mathrm{FAB}$ & 14 & 12 & 18 & 17 \\
\hline FAB after follow-up & 12 & 17 & 15 & 18 \\
\hline Mental speed/attention & Slightly decreased & Slightly decreased & Decreased & Normal \\
\hline Executive tasks & Mildly disturbed & Mildly disturbed & Mildly disturbed & Normal \\
\hline Episodic memory & Normal & Mildly disturbed & Normal & Normal \\
\hline $\begin{array}{l}\text { Semantic memory } \\
\text { (category fluency) }\end{array}$ & Normal & Mildly disturbed & Normal & Normal \\
\hline Visuospatial functions & Normal & Normal & Normal & Normal \\
\hline Language & Normal & Normal & Normal & Normal \\
\hline \multicolumn{5}{|l|}{ Social cognition } \\
\hline $\begin{array}{l}\text { Social cognition profile } \\
\text { (faux pas, Eckman faces) }\end{array}$ & $\mathrm{n} / \mathrm{a}$ & $\begin{array}{l}\text { Impaired, no recognition } \\
\text { of faux pas, impaired } \\
\text { recognition of disgust }\end{array}$ & $\begin{array}{l}\text { Impaired, no recognition } \\
\text { of faux pas, impaired } \\
\text { recognition of sadness }\end{array}$ & $\begin{array}{l}\text { Impaired recognition } \\
\text { of sadness }\end{array}$ \\
\hline \multicolumn{5}{|l|}{ Biomarkers } \\
\hline MRI: Fazekas & 1 & 1 & 0 & 0 \\
\hline MRI: MTA & $0 / 0$ & $1 / 1$ & $0 / 0$ & $\mathrm{I} / \mathrm{I}$ \\
\hline MRI: GCA & 0 & I & Frontal 2, parietal I, global I & 0 \\
\hline FDG-PET & Normal & $\mathrm{n} / \mathrm{a}$ & Normal & Normal \\
\hline PIB-PET & $\mathrm{n} / \mathrm{a}$ & $\mathrm{n} / \mathrm{a}$ & Normal & $\mathrm{n} / \mathrm{a}$ \\
\hline $\begin{array}{l}\text { CSF: amyloid beta- } 42 \\
(>550 \mathrm{pg} / \mathrm{mL})\end{array}$ & I,07| & 632 & $\mathrm{n} / \mathrm{a}$ & 880 \\
\hline CSF: tau $(<375 \mathrm{pg} / \mathrm{mL})$ & 400 & 202 & $\mathrm{n} / \mathrm{a}$ & 486 \\
\hline CSF: P-tau (<52 pg/mL) & 58 & 36 & $\mathrm{n} / \mathrm{a}$ & 66 \\
\hline
\end{tabular}

Abbreviations: CSF, cerebrospinal fluid; FAB, frontal assessment battery; FDG-PET, [ $\left.{ }^{18} \mathrm{~F}\right]$-2-deoxy-2-fluoro-D-glucose positron emission tomography; GCA, global cortical atrophy; MMSE, Mini-Mental State Examination; MRI, magnetic resonance imaging; MTA, medial temporal lobe atrophy; +, present; n/a, not applicable; PIB-PET, Pittsburgh compound B positron emission tomography; P-tau, phosphorylated tau.

obsessive compulsive personality disorder more than 10 years ago and had been stable on a MAO inhibitor (Table 1). In the last year, he experienced vivid visual hallucinations that initially started during acute medical illness (repeated bout of pneumonia) but persisted after resolution of the medical events at night. His wife and daughter reported increased obsessive compulsive behavior with verbal aggression toward strangers if his routine got disturbed. Furthermore, he tried to force his wife to excessively buy items and was increasingly snacking. His daughter noticed that he had very little interest in others and did not take initiative in social contact nor did he seem to notice the needs of others. His family history was 
negative for psychiatric disorders and dementia. At neurological examination, there were no extrapyramidal signs. His MMSE was 27/30 and FAB 18/18. He had a high score on stereotypical symptoms (SRI 20/60), which according to his family could not be attributed to his premorbid personality. Repeated neuropsychological examination revealed very slowly progressive mild executive disturbances with decreased mental speed, with MMSE 23/30 and FAB 15/18. His MRI scans showed nonprogressive frontoparietal atrophy after 3 years of follow-up, while his FDG- and Pittsburgh compound B-PET scans were completely normal. His behavioral symptoms could not be accounted for by obsessive compulsive personality disorder, bipolar mood symptoms, or a progressive neurodegenerative disorder.

\section{Case 4}

A 62-year-old male visited our memory clinic with progressive memory complaints. He noticed word-finding difficulties and using wrong words. He had been diagnosed with bipolar 1 disorder 30 years ago and had been hospitalized for bipolar mania 6 months before his memory complaints started (Table 1). His mood was euthymic and controlled with lithium and olanzapine. Lithium serum levels were within the therapeutic range $(0.4-0.8 \mathrm{mmol} / \mathrm{L})$ and reducing the dose did not change his behavior. According to his wife, he frequently misused words and his speech had slowed. After recovery from his mania, his social judgment remained impaired (eg, asking a 6-year-old unknown girl to accompany him on a canoe trip, talking excessively during a funeral speech, making personal comments to female strangers). His family history was negative for psychiatric disorders or dementia. Except the presence of a mildly slurred speech, no neurological abnormalities were present. At repeated neuropsychological examination, there were no disturbances, with an initial MMSE 28/30 and FAB 17/18. His MRI scan showed medial temporal atrophy grade 1 on both sides without any other abnormalities, and his FDG-PET was within normal range. His CSF had normal amyloid beta-42 $(880 \mathrm{pg} / \mathrm{mL})$, with slightly elevated tau and phosphorylated tau (486 and $66 \mathrm{pg} / \mathrm{mL}$, respectively). After 3 years of follow-up, his mood remained stable. His wife reported that he had regained some of his empathy, but was not at his usual level of concern for others. His speech impairments remained static. Repeated MMSE and FAB scores were 29/30 and 18/18, respectively. A repeated MRI scan after 2 years showed no increase of atrophy. His changed behavior could not be accounted for by progressive neurodegenerative disorder after 3 years of follow-up.

\section{Discussion}

We present four older male patients with early- and lateonset bipolar disorder who had behavioral and functional impairment consistent with a frontal lobe syndrome. Their informant-based report suggested that this condition was clinically distinct from symptoms characteristic of these individuals' previous manic or depressive symptoms. After screening for cognitive and executive deficits, few impairments were found, as shown by relatively high MMSE and FAB scores. At neuropsychological testing, there was only mild impairment in mental speed and executive functions. Most profound was their lack of insight and empathy. All four displayed disinhibition and stereotyped behavior, whereas apathy was a significant feature in two cases. All cases fulfilled the Rascovsky criteria for "possible" bvFTD; ${ }^{17}$ however, after 3 to 7 years of follow-up, there was no progression to "probable" bvFTD since no significant functional decline over time or progressive frontotemporal deficits on neuroimaging developed.

In these cases, the age-related MRI findings and absence of cognitive deficits in multiple domains suggest no comorbid dementia, although we cannot entirely rule out case 2 as having early-stage dementia. Although white matter hyperintensities are frequently reported in older bipolar patients, our cases had low Fazekas scores, indicating that their clinical profile was not related to vascular pathology. Two cases had slightly elevated tau levels suggestive of axonal degeneration. However, their normal amyloid beta- 42 levels and lack of progressive deterioration make a neurodegenerative cause unlikely.

A similar clinical picture with emotional blunting after manic-depressive episodes has been described in the early 20th century as "dementia maniaco-depressionis". ${ }^{18}$ The clinical picture described here does not appear to be just a result of pharmacotherapy. Furthermore, with an average of two admissions in our patients and a disease duration ranging from 14 to 60 years, it is not possible to link presumed toxic effects of mood episodes to their current symptoms.

A proportion of bvFTD patients have a slow course with relatively normal neuroimaging, particularly those carrying a C9orf72 repeat expansion. ${ }^{19}$ This repeat expansion has been found in patients with bipolar disorder preceding FTD; ${ }^{20,21}$ however, this mutation was not detected in a cohort of 206 patients with bipolar disorder. ${ }^{22} \mathrm{C} 9$ orf72 mutations were excluded as a possible cause of the clinical syndrome in our cases.

Deficits in emotion recognition and theory of mind have been recognized as hallmarks of bipolar disorder. ${ }^{23}$ 
Moreover, they have been reported as an early phenomenon in bvFTD. ${ }^{24,25}$ Executive disturbances are the most prominent feature in the neuropsychological examination in bvFTD, however executive impairment is common in elderly patients with bipolar disorder as well. ${ }^{26,27}$

A possible link between bipolar disorder and bvFTD has also been suggested by case reports on patients presenting with manic symptoms as a first manifestation of bvFTD ${ }^{28,29}$ and patients with a lifetime diagnosis of bipolar disorder evolving into bvFTD. ${ }^{30,31}$ This large clinical overlap in social cognition, executive disturbances, and behavioral profiles might be explained by the involvement of common functional neuroanatomical networks. ${ }^{32-34}$

The condition fulfilling criteria for possible bvFTD failing to convert to probable bvFTD over time is labeled benign bvFTD phenocopy syndrome. ${ }^{35,36}$ These patients exhibit behavioral and functional impairments consistent with a frontal lobe syndrome but fail to progress over time and have no frontal or anterior temporal atrophy or hypoperfusion at follow-up. Although an alternative explanation is generally lacking in these cases, end-stage bipolar disorder may be one of the underlying causes of this syndrome, with a male predominance as in our cases.

\section{Conclusion}

To the best of our knowledge, there have been no previous case series of older patients with bipolar disorder illustrating progressive behavioral change culminating in frontal lobe syndrome. In all four cases, behaviors could not be attributed to bipolar mood symptoms and were reported as a distinct loss of insight and empathy with disinhibition and socially inappropriate behavior. In spite of the limitations imposed by our small sample size, confined psychiatric follow-up, and lack of postmortem evaluation to rule out other pathological explanations, the clinical implications of our case series are potentially valuable. The recognition of this phenotype is important for the understanding of brainbehavior relationships, in particular, the pathophysiology of bipolar disorder. Our case series is a reminder that clinicians should reject a diagnosis of bvFTD in patients with bipolar disorder in the absence of obvious clinical and radiological progression over time.

\section{Acknowledgments}

The authors thank Piet Eikelenboom for his comments on the previous versions of the manuscript. No financial support was received for this study.

\section{Disclosure}

The authors report no conflicts of interest in this work.

\section{References}

1. Samame C, Martino DJ, Strejilevich SA. A quantitative review of neurocognition in euthymic late-life bipolar disorder. Bipolar Disord. 2013;15(6):633-644.

2. Gildengers AG, Chisholm D, Butters MA, et al. Two-year course of cognitive function and instrumental activities of daily living in older adults with bipolar disorder: evidence for neuroprogression? Psychol Med. 2013;43(4):801-811.

3. Schouws SN, Stek ML, Comijs HC, Dols A, Beekman AT. Cognitive decline in elderly bipolar disorder patients: a follow-up study. Bipolar Disord. 2012;14(7):749-755.

4. Delaloye C, Moy G, de Bilbao F, et al. Longitudinal analysis of cognitive performances and structural brain changes in late-life bipolar disorder. Int J Geriatr Psychiatry. 2011;26(12):1309-1318.

5. Depp CA, Savla GN, Moore DJ, et al. Short-term course of neuropsychological abilities in middle-aged and older adults with bipolar disorder. Bipolar Disord. 2008;10(6):684-690.

6. Martino DJ, Strejilevich SA, Marengo E, et al. Relationship between neurocognitive functioning and episode recurrences in bipolar disorder. $J$ Affect Disord. 2012;147(1-3):345-351.

7. Beyer JL, Kuchibhatla M, Payne M, et al. Caudate volume measurement in older adults with bipolar disorder. Int J Geriatr Psychiatry. 2004; 19(2):109-114.

8. Haller S, Xekardaki A, Delaloye C, et al. Combined analysis of grey matter voxel-based morphometry and white matter tract-based spatial statistics in late-life bipolar disorder. J Psychiatry Neurosci. 2011;36(6):391-401.

9. Versace A, Almeida JR, Hassel S, et al. Elevated left and reduced right orbitomedial prefrontal fractional anisotropy in adults with bipolar disorder revealed by tract-based spatial statistics. Arch Gen Psychiatry. 2008;65(9):1041-1052.

10. Vederine FE, Wessa M, Leboyer M, Houenou J. A meta-analysis of whole-brain diffusion tensor imaging studies in bipolar disorder. Prog Neuropsychopharmacol Biol Psychiatry. 2011;35(8):1820-1826.

11. Gildengers AG, Chung KH, Huang SH, Begley A, Aizenstein HJ, Tsai SY. Neuroprogressive effects of lifetime illness duration in older adults with bipolar disorder. Bipolar Disord. 2014;16(6):617-623.

12. Berk M, Kapczinski F, Andreazza AC, et al. Pathways underlying neuroprogression in bipolar disorder: focus on inflammation, oxidative stress and neurotrophic factors. Neurosci Biobehav Rev. 2010;35(3):804-817.

13. Rizzo LB, Costa LG, Mansur RB, et al. The theory of bipolar disorder as an illness of accelerated aging: implications for clinical care and research. Neurosci Biobehav Rev. 2014;42:157-169.

14. Berk M, Hallam KT, McGorry PD. The potential utility of a staging model as a course specifier: a bipolar disorder perspective. $J$ Affect Disord. 2007;100(1-3):279-281.

15. Kapczinski F, Dias VV, Kauer-Sant'Anna M, et al. Clinical implications of a staging model for bipolar disorders. Expert Rev Neurother. 2009; 9(7):957-966.

16. McGorry PD, Purcell R, Hickie IB, Yung AR, Pantelis C, Jackson HJ. Clinical staging: a heuristic model for psychiatry and youth mental health. Med J Aust. 2007;187(7 Suppl):S40-S42.

17. Rascovsky K, Hodges JR, Knopman D, et al. Sensitivity of revised diagnostic criteria for the behavioural variant of frontotemporal dementia. Brain. 2011;134(Pt 9):2456-2477.

18. Ritterhaus E. Die klinische Stellung des manisch-depressiven Irreseins. [The clinical status of manic depressive illness]. Z ges Neurol Psychiat. 1921;II(72):320-346. German.

19. Khan BK, Yokoyama JS, Takada LT, et al. Atypical, slowly progressive behavioural variant frontotemporal dementia associated with C9ORF72 hexanucleotide expansion. J Neurol Neurosurg Psychiatry. 2012; 83(4):358-364. 
20. Meisler MH, Grant AE, Jones JM, et al. C9ORF72 expansion in a family with bipolar disorder. Bipolar Disord. 2013;15(3):326-332.

21. Floris G, Di Stefano F, Pisanu C, et al. C9ORF72 repeat expansion and bipolar disorder - is there a link? No mutation detected in a Sardinian cohort of patients with bipolar disorder. Bipolar Disord. 2014;16(6):667-668.

22. Floris G, Borghero G, Cannas A, et al. Bipolar affective disorder preceding frontotemporal dementia in a patient with C9ORF72 mutation: is there a genetic link between these two disorders? J Neurol. 2013; 260(4):1155-1157.

23. Samame C. Social cognition throughout the three phases of bipolar disorder: a state-of-the-art overview. Psychiatry Res. 2013;210(3): 1275-1286.

24. Gregory C, Lough S, Stone V, et al. Theory of mind in patients with frontal variant frontotemporal dementia and Alzheimer's disease: theoretical and practical implications. Brain. 2002;125(Pt 4):752-764.

25. Lough S, Kipps CM, Treise C, Watson P, Blair JR, Hodges JR. Social reasoning, emotion and empathy in frontotemporal dementia. Neuropsychologia. 2006;44(6):950-958.

26. Schouws SN, Comijs HC, Stek ML, et al. Cognitive impairment in early and late bipolar disorder. Am J Geriatr Psychiatry. 2009;17(6):508-515.

27. Martino DJ, Strejilevich SA, Manes F. Neurocognitive functioning in early-onset and late-onset older patients with euthymic bipolar disorder. Int J Geriatr Psychiatry. 2013;28(2):142-148.

28. Vorspan F, Bertoux M, Brichant-Petitjean C, Dubois B, Lepine JP. Relapsing-remitting behavioural variant of frontotemporal dementia in a bipolar patient. Funct Neurol. 2012;27(3):193-196.

29. Kerstein AH, Schroeder RW, Baade LE, Lincoln J, Khan AY. Frontotemporal dementia mimicking bipolar disorder. J Psychiatr Pract. 2013; 19(6):498-500.
30. Cerami C, Marcone A, Galimberti D, Villa C, Scarpini E, Cappa SF. From genotype to phenotype: two cases of genetic frontotemporal lobar degeneration with premorbid bipolar disorder. J Alzheimers Dis. 2011; 27(4):791-797.

31. Pavlovic A, Marley J, Sivakumar V. Development of frontotemporal dementia in a case of bipolar affective disorder: is there a link? BMJ Case Rep. 2011;2011.

32. Zhou J, Seeley WW. Network dysfunction in Alzheimer's disease and frontotemporal dementia: implications for psychiatry. Biol Psychiatry. 2014;75(7):565-573.

33. Rashid B, Damaraju E, Pearlson GD, Calhoun VD. Dynamic connectivity states estimated from resting fMRI Identify differences among schizophrenia, bipolar disorder, and healthy control subjects. Front Hum Neurosci. 2014;8:897.

34. Lois G, Linke J, Wessa M. Altered functional connectivity between emotional and cognitive resting state networks in euthymic bipolar I disorder patients. PLoS One. 2014;9(10):e107829.

35. Kipps CM, Hodges JR, Hornberger M. Nonprogressive behavioural frontotemporal dementia: recent developments and clinical implications of the 'bvFTD phenocopy syndrome'. Curr Opin Neurol. 2010; 23(6):628-632.

36. Davies RR, Kipps CM, Mitchell J, Kril JJ, Halliday GM, Hodges JR. Progression in frontotemporal dementia: identifying a benign behavioral variant by magnetic resonance imaging. Arch Neurol. 2006; 63(11):1627-1631.
Neuropsychiatric Disease and Treatment

\section{Publish your work in this journal}

Neuropsychiatric Disease and Treatment is an international, peerreviewed journal of clinical therapeutics and pharmacology focusing on concise rapid reporting of clinical or pre-clinical studies on a range of neuropsychiatric and neurological disorders. This journal is indexed on PubMed Central, the 'PsycINFO' database and CAS,

\section{Dovepress}

and is the official journal of The International Neuropsychiatric Association (INA). The manuscript management system is completely online and includes a very quick and fair peer-review system, which is all easy to use. Visit http://www.dovepress.com/testimonials.php to read real quotes from published authors. 